\title{
Adipose tissue fatty acid metabolism in insulin-resistant men
}

\author{
A. S. T. Bickerton - R. Roberts $\cdot$ B. A. Fielding • \\ H. Tornqvist • E. E. Blaak • A. J. M. Wagenmakers • \\ M. Gilbert • S. M. Humphreys • F. Karpe • K. N. Frayn
}

Received: 20 March 2008 / Accepted: 5 April 2008/Published online: 27 May 2008

(C) Springer-Verlag 2008

\begin{abstract}
Aims/hypothesis Increased NEFA production and concentrations may underlie insulin resistance. We examined systemic and adipose tissue NEFA metabolism in insulinresistant overweight men (BMI $25-35 \mathrm{~kg} / \mathrm{m}^{2}$ ).

Methods In a cohort study we examined NEFA concentrations in men in the upper quartile of fasting insulin $(n=124)$ and in men with fasting insulin below the median $(n=159)$. In a metabolic study we examined NEFA metabolism in the fasting and postprandial states, in ten insulin-resistant men and ten controls.

Results In the cohort study, fasting NEFA concentrations were not significantly different between the two groups (median values: insulin-resistant men, $410 \mu \mathrm{mol} / \mathrm{l}$; controls,
\end{abstract}

A. S. T. Bickerton • R. Roberts $\cdot$ B. A. Fielding $\cdot$ M. Gilbert

S. M. Humphreys $\cdot$ F. Karpe $\cdot$ K. N. Frayn $(\bowtie)$

Oxford Centre for Diabetes, Endocrinology and Metabolism,

University of Oxford, Churchill Hospital,

Oxford OX3 7LJ, UK

e-mail: keith.frayn@oxlip.ox.ac.uk

H. Tornqvist

Clinical Sciences, Diabetes and Endocrinology,

Malmö University Hospital, Lund University,

Malmö, Sweden

H. Tornqvist

R\&D, Novo Nordisk A/S,

Bagsværd, Denmark

E. E. Blaak

NUTRIM, University of Maastricht,

Maastricht, The Netherlands

A. J. M. Wagenmakers

School of Sport and Exercise Sciences,

University of Birmingham,

Birmingham, UK
$445 \mu \mathrm{mol} / \mathrm{l})$. However, triacylglycerol concentrations differed markedly (1.84 vs $1.18 \mathrm{mmol} / \mathrm{l}$ respectively, $p<0.001)$. In the metabolic study, arterial NEFA concentrations again did not differ between groups, whereas triacylglycerol concentrations were significantly higher in insulin-resistant men. Systemic NEFA production and the release of NEFA from subcutaneous adipose tissue, expressed per unit of fat mass, were both reduced in insulin-resistant men compared with controls (fasting values by $32 \%, p=0.02$, and $44 \%, p=0.04$ respectively). 3 -Hydroxybutyrate concentrations, an index of hepatic fat oxidation and ketogenesis, were lower $(p=0.03)$.

Conclusions/interpretation Adipose tissue NEFA output is not increased (per unit weight of tissue) in insulin resistance. On the contrary, it appears to be suppressed by high fasting insulin concentrations. Alterations in triacylglycerol metabolism are more marked than those in NEFA metabolism and are indicative of altered metabolic partitioning of fatty acids (decreased oxidation, increased esterification) in the liver.

Keywords Adipose tissue · Insulin resistance .

Non-esterified fatty acids $\cdot$ Triacylglycerol

\author{
Abbreviations \\ OBB Oxford Biobank \\ 3OHB 3-hydroxybutyrate \\ $\mathrm{Ra}_{\mathrm{NEFA}}$ rate of appearance of NEFA
}

\section{Introduction}

Insulin resistance is closely associated with disturbance of fat metabolism. Its manifestations include dyslipidaemia 
with elevated triacylglycerol and depressed HDL-cholesterol concentrations. In addition, it is widely believed that the origins of insulin resistance lie in increased supply of NEFA (also known as free fatty acids, FFA) [1-3]. Increased fatty acid supply may lead to fat deposition in insulin target tissues such as liver and skeletal muscle. This 'ectopic' fat deposition is intimately related to the development of insulin resistance, the phenomenon known as lipotoxicity [4].

Circulating NEFA arise from lipolysis in adipose tissue. Adipose tissue accumulation is typically associated with insulin resistance, and it would be reasonable to suppose that increased fat mass will increase circulating NEFA concentrations. Indeed, there is evidence for increased NEFA concentrations in obese people $[5,6]$, although this is not a universal finding (reviewed below). Abdominal obesity, in particular, is associated with insulin resistance, and it seems relevant that subcutaneous abdominal fat is the major depot contributing to systemic NEFA concentrations [7]. People with abdominal obesity tend to have higher circulating NEFA concentrations than do BMI-matched people with lower-body fat distribution [8].

Substantial evidence has been interpreted to show that NEFA supply in various insulin-resistant states is increased because the regulation of adipose tissue lipolysis itself also becomes resistant to insulin. NEFA are released in the postabsorptive state mainly from the hydrolysis of triacylglycerol stored in adipocytes. This process is suppressed by insulin in the period following a meal. Both fasting NEFA concentrations and the failure to suppress NEFA under euglycaemic-hyperinsulinaemic clamp conditions have been correlated with measures of insulin resistance in healthy individuals [9]. Defects in insulin-mediated suppression of NEFA concentrations have been shown in obesity [10], in impaired glucose tolerance [11] and in patients with type 2 diabetes [12]. Plasma NEFA concentrations are potentially also regulated by the rate of removal from the circulation. An impairment of NEFA uptake by muscle has been demonstrated in obesity [13], in impaired glucose tolerance [14] and in type 2 diabetes [15]. Increasing NEFA oxidation in insulin-resistant men by peroxisome proliferator-activated receptor- $\delta$ activation markedly lowers NEFA concentrations [16].

The literature, however, is inconsistent. In some studies, even extremely obese people have normal circulating NEFA concentrations [17]. It may be that a consistent elevation of NEFA concentrations in obesity occurs only in the presence of type 2 diabetes [18]. In those studies showing elevated NEFA concentrations in obesity, the degree of elevation is not simply proportional to the increase in fat mass. For instance, Opie and Walfish [5] showed that fasting NEFA concentrations were elevated by some $60 \%$ in grossly obese people compared with lean controls, but the difference in adipose tissue mass was more than tenfold. This does not seem to be compatible with the idea that insulin resistance of lipolysis further increases NEFA delivery from adipose tissue. It is also important to recognise that euglycaemic-hyperinsulinaemic clamp conditions, with controlled insulin concentrations, may not mimic normal daily life, in which insulin-resistant individuals will display hyperinsulinaemia, especially after meals, and that it is not clear how that would affect the regulation of NEFA supply. There is little information regarding adipose tissue fatty acid metabolism and its regulation in relation to insulin resistance under the normal physiological conditions of fasting and feeding.

We therefore set out to test the hypothesis that disturbances of the regulation of adipose tissue lipolysis and excess circulating NEFA concentrations characterise insulin-resistant individuals. We studied circulating NEFA concentrations in relation to other metabolic parameters in a large cohort of overweight, but healthy men stratified by fasting insulin concentration. We also conducted a detailed study of systemic, adipose tissue and skeletal muscle fatty acid metabolism in subgroups selected from this cohort, using stable-isotope tracer methodology combined with arterio-venous measurements as described recently [19].

\section{Methods}

\section{Cohort study}

The Oxford Biobank (OBB), a population-based random collection of healthy men and women aged 30 to 50 years [20], was used for the cohort study. Individuals on the OBB register have previously had measurements of biochemical (fasting plasma insulin, glucose, HDL-cholesterol, triacylglycerol, NEFA) and anthropometric (height, weight, waist, hip, blood pressure, body composition) parameters. Overweight men with a BMI of 25 to $35 \mathrm{~kg} / \mathrm{m}^{2}$ were included in the present analysis. Comparisons were made between a group with low and a group with high fasting insulin concentrations, taking this as a proxy measure of insulin resistance. To ensure clear separation between groups, men selected for the control group had fasting insulin concentrations below the median for the entire OBB population (51.6 pmol/1). They were compared with men with fasting insulin concentrations within the upper quartile of the whole OBB population (above $76.2 \mathrm{pmol} / \mathrm{l}$ ).

Metabolic investigation

Participants We recruited 20 overweight men from the cohort described above for detailed metabolic investigation. Thus, their BMI was between 25 and $35 \mathrm{~kg} / \mathrm{m}^{2}$ when 
recruited into the OBB. Of these 20 men, ten were selected from those with fasting insulin concentrations below the median for the entire OBB population and ten from the upper quartile of that population. This was to ensure that the groups included those at the extremes of insulin sensitivity and resistance. At the time of the detailed metabolic study, some of these parameters had changed. We therefore divided the whole group on the basis of their median fasting insulin concentration at the time of the study ( $88.8 \mathrm{pmol} / \mathrm{l})$ and regarded the ten men above the median for fasting insulin as the insulin-resistant group, and the remaining ten men as the insulin-sensitive group. However, recognising that insulin resistance constitutes a continuum, we looked at some of our key results in terms of relationships with insulin sensitivity/resistance across the whole group.

Individuals taking any medication affecting lipid metabolism were excluded from this metabolic study cohort and no participant recruited was known to have diabetes. Fat mass was estimated using a bioimpedance analyser (Bodystat-1500; Bodystat, Isle of Man, UK). Participants were studied following an overnight fast that commenced at 20:00 hours on the evening before the study, and asked to refrain from strenuous exercise and alcohol for $24 \mathrm{~h}$ prior to the study. All participants gave written informed consent and the study was approved by the Oxfordshire Clinical Research Ethics Committee. Data from some participants have been previously reported as part of a more detailed study of lipid handling in adipose tissue, not relating to insulin sensitivity [19].

Study protocol On the study day, serial blood samples were taken in the fasting state and for $6 \mathrm{~h}$ after ingestion of a mixed test meal consisting of $40 \mathrm{~g}$ fat, $40 \mathrm{~g}$ carbohydrate and $100 \mathrm{mg}\left[\mathrm{U}_{-}{ }^{13} \mathrm{C}\right]$ palmitic acid (isotope purity $98 \%$; CK Gas Products, Hook, UK). All sample timing is relative to the start of the meal (time 0). Participants also received a continuous intravenous infusion of $\left[{ }^{2} \mathrm{H}_{2}\right]$ palmitic acid (isotope purity 97\%; CK Gas Products) complexed to human albumin (infusion rate $0.04 \mu \mathrm{mol} \mathrm{kg}{ }^{-1} \mathrm{~min}^{-1}$ ). The infusion was started $60 \mathrm{~min}$ prior to the blood sample at $-60 \mathrm{~min}$ to allow for equilibration of tracer.

Blood sampling The superficial epigastric vein was cannulated, as previously described [21] in order to sample the venous effluent of subcutaneous abdominal adipose tissue. This vein carries a negligible metabolic contribution of blood from other tissues. Arterial blood was sampled from the femoral artery. Venous blood from forearm muscle was obtained from a cannula placed retrogradely in a deep antecubital vein. In order to avoid contamination of the blood from the forearm muscle with blood from the hand, a wrist cuff was inflated to $200 \mathrm{mmHg}$ for $3 \mathrm{~min}$ before taking samples. Blood sampling was performed simultaneously from all three sites.
Tissue blood flow Subcutaneous abdominal adipose tissue blood flow was measured by ${ }^{133} \mathrm{Xe}$ washout [22]. Forearm muscle blood flow was assessed by venous occlusion strain-gauge plethysmography with an inflated wrist cuff [23]. Blood flow measurements were made immediately following blood sampling.

Analyses Whole blood was collected into heparinised syringes (Sarstedt, Leicester, UK) for measurement of metabolite and insulin concentrations. Plasma glucose, triacylglycerol and NEFA concentrations were determined enzymatically using a multianalyser (ILab $600 \mathrm{M}$; Instrumentation Laboratory, Warrington, UK). Whole blood for 3-hydroxybutyrate (3OHB) measurement was deproteinised with 7\% (wt/vol.) perchloric acid and concentrations were measured enzymatically. Insulin was determined by radioimmunoassay (Linco Research, St Charles, MO, USA). Fatty acid composition and isotopic enrichment were determined as previously described [19].

Calculations The homeostasis model assessment of insulin resistance was calculated from fasting plasma insulin and glucose concentrations [24].

Plasma concentrations of lipids were converted to whole-blood concentrations using the packed cell volume. Arterio-venal and veno-arterial differences in metabolite concentrations (labelled and unlabelled) were calculated across adipose tissue and forearm. Net flux (uptake or release) was calculated as the product of arterio-venal or veno-arterial difference and tissue blood flow. A positive arterio-venal difference in metabolite concentrations implies net uptake or extraction across a tissue, whereas a positive veno-arterial difference implies net release from a tissue. Fractional NEFA and triacylglycerol extraction were calculated as the arteriovenal difference divided by the respective arterial concentration. Clearance of triacylglycerol, a measure of the efficiency of substrate removal from the circulation, was calculated as the product of fractional extraction and tissue blood flow [25]. Absolute (unidirectional) extraction of NEFA by muscle was taken as the arterial NEFA concentration multiplied by the forearm clearance of plasma $\left[{ }^{2} \mathrm{H}_{2}\right]$ palmitate. The whole-body rate of appearance of NEFA $\left(\mathrm{Ra}_{\mathrm{NEFA}}\right)$ was derived from arterial tracer: tracee ratios of $\left[{ }^{2} \mathrm{H}_{2}\right]$ palmitate. Steele's equation modified for use with stable isotopes [26] was used to calculate $\mathrm{Ra}_{\mathrm{NEFA}}$ at each timepoint [27].

Statistical methods

Data were analysed using SPSS for Windows version 10 (SPSS UK, Chertsey, UK). Statistical significance was set at $p<0.05$. Data for the cohort study are presented as medians \pm interquartile range and the Mann-Whitney $U$ test was used to detect differences between groups. Data from 
the metabolic investigation are presented as means \pm SEM unless otherwise stated. Repeated measures ANOVA was used to determine differences between the groups over the whole study period. Data were log-transformed when appropriate for analysis. Areas under the curves were calculated by the trapezoid method. The Mann-Whitney or unpaired $t$ tests were used to compare mean fasting parameters and AUCs depending upon whether data were normally distributed. Spearman correlation coefficients were used to describe the relationship between NEFA output and insulin concentration.

\section{Results}

\section{Cohort study}

There were 636 men with a BMI of 25 to $35 \mathrm{~kg} / \mathrm{m}^{2}$ in the OBB. Of these, 159 had fasting arterial insulin concentrations below the median for the whole OBB population and 124 had fasting arterial insulin concentrations in the upper quartile for the OBB population. Biochemical and anthropometric indices in these groups are compared on Table 1. Fasting insulin concentrations were well separated, by definition. The groups were well matched for age. Despite significant differences in many parameters measured ( $p<0.01$ for weight, BMI, waist circumference, blood pressure, triacylglycerol, glucose, HDL-cholesterol), there was no difference in fasting plasma NEFA concentration between the two groups. Total cholesterol concentrations were also similar in the groups.
Metabolic investigation

The clinical and metabolic characteristics of the subgroups participating in the metabolic study are summarised in Table 2. As with the cohort study, fasting plasma insulin concentrations were different by definition and age was well matched. The BMI differed between the groups by about the same proportion as in the cohort study, but was not significantly different between groups. However, the insulin-resistant group had significantly greater fat mass than the controls. The most striking metabolic difference was in fasting triacylglycerol concentrations $(p=0.01)$, but, as in the cohort study, fasting plasma NEFA concentrations were not different between the groups.

Systemic responses and tissue blood flow Arterial insulin concentrations (Fig. 1a) in the insulin-resistant group were elevated compared with the controls in the fasting state (by definition) and throughout the postprandial period. In contrast, plasma glucose concentrations (Fig. 1b) in the two groups were identical throughout the experiment. Plasma triacylglycerol concentrations (Fig. 1c) were greater in the insulin-resistant group than in the control group in the fasting $(p=0.012)$ and postprandial states, whereas $3 \mathrm{OHB}$ concentrations (Fig. 1d) were lower in the insulinresistant group than in controls, both in the fasting state $(p=0.06)$, and over the whole time-course (Fig. 1).

Forearm blood flow was relatively steady during the study and did not differ between groups. Adipose tissue blood flow tended to be lower in the insulin-resistant group than among controls, with less response to the test meal.

Table 1 Characteristics of participants in the cohort study

\begin{tabular}{|c|c|c|c|c|c|}
\hline & \multicolumn{2}{|c|}{ Controls $(n=159)$} & \multicolumn{3}{|c|}{ Insulin-resistant $(n=124)$} \\
\hline & Median & Interquartile range & Median & Interquartile range & $p$ value \\
\hline Age (years) & 43 & $36-45$ & 43 & $40-45$ & 0.989 \\
\hline Weight (kg) & 85.0 & $81.0-92.1$ & 92.5 & $85.3-98$ & $<0.001$ \\
\hline $\operatorname{BMI}\left(\mathrm{kg} / \mathrm{m}^{2}\right)$ & 26.8 & $25.6-28.5$ & 28.9 & $27.1-31.2$ & $<0.001$ \\
\hline Waist (cm) & 94.0 & $89.0-99.0$ & 99.0 & $94.0-105.0$ & $<0.001$ \\
\hline Insulin $(\mathrm{pmol} / \mathrm{l})$ & 40.2 & $31.8-46.2$ & 90.0 & $82.8-110.4$ & $(<0.001)$ \\
\hline Glucose $(\mathrm{mmol} / \mathrm{l})$ & 5.17 & $5.00-5.43$ & 5.51 & $5.2-5.92$ & $<0.001$ \\
\hline HOMA-IR & 1.53 & $1.20-1.80$ & 3.77 & $3.32-4.48$ & $<0.001$ \\
\hline NEFA $(\mu \mathrm{mol} / \mathrm{l})$ & 445 & $309-561$ & 410 & $314-548$ & 0.668 \\
\hline Triacylglycerol (mmol/l) & 1.18 & $0.85-1.62$ & 1.84 & $1.36-2.56$ & $<0.001$ \\
\hline Total cholesterol (mmol/l) & 5.6 & $5.0-6.3$ & 5.8 & $5.0-6.5$ & 0.264 \\
\hline HDL-cholesterol (mmol/l) & 1.23 & $1.06-1.40$ & 1.13 & $0.98-1.31$ & 0.001 \\
\hline Systolic BP & 125 & $118-132$ & 128 & $120-137$ & 0.006 \\
\hline Diastolic BP & 80 & $76-85$ & 86 & $81-93$ & $<0.001$ \\
\hline
\end{tabular}

Participants with BMI $25-35 \mathrm{~kg} / \mathrm{m}^{2}$ were selected from the Oxford Biobank on the basis of fasting plasma insulin concentration, as described in the Methods

Statistical differences were calculated by Mann-Whitney test

HOMA-IR, homeostasis model assessment of insulin resistance 
Table 2 Baseline characteristics of participants in the detailed metabolic study

\begin{tabular}{|c|c|c|c|c|c|}
\hline & \multicolumn{2}{|c|}{ Controls $(n=10)$} & \multicolumn{3}{|c|}{ Insulin-resistant $(n=10)$} \\
\hline & Median & Interquartile range & Median & Interquartile range & $p$ value \\
\hline Age (years) & 44 & $32-54$ & 44 & $34-49$ & 0.63 \\
\hline Weight (kg) & 85.7 & $76.5-99.3$ & 92.8 & $73.3-109.9$ & 0.14 \\
\hline BMI $\left(\mathrm{kg} / \mathrm{m}^{2}\right)$ & 27.2 & $22.8-31.8$ & 29.7 & $25.3-34.6$ & 0.14 \\
\hline Fat mass $(\mathrm{kg})$ & 17.9 & $10.8-22.0$ & 20.3 & $17.2-31.8$ & 0.04 \\
\hline Waist (cm) & 94.0 & $86.0-108.0$ & 100.5 & $86.0-112.0$ & 0.06 \\
\hline Insulin (pmol/1) & 57.6 & $29.4-87.6$ & 103.8 & $89.4-172.2$ & $(0.00)$ \\
\hline Glucose (mmol/l) & 5.61 & $4.65-6.31$ & 5.55 & $4.43-6.60$ & 0.97 \\
\hline HOMA-IR & 2.33 & $1.30-3.89$ & 4.43 & $3.15-7.66$ & 0.001 \\
\hline NEFA $(\mu \mathrm{mol} / 1)$ & 672 & $437-843$ & 591 & $367-803$ & 0.28 \\
\hline Triacylglycerol (mmol/l) & 0.96 & $0.70-2.43$ & 2.04 & $1.14-3.28$ & 0.01 \\
\hline HDL-cholesterol (mmol/1) & 1.09 & $0.89-1.67$ & 1.07 & $0.91-1.25$ & 0.63 \\
\hline Systolic BP & 123 & $104-143$ & 131 & $122-153$ & 0.09 \\
\hline Diastolic BP & 80 & $75-98$ & 86 & $73-96$ & 0.14 \\
\hline
\end{tabular}

Plasma data refer to fasting concentrations

Statistical differences were calculated by Mann-Whitney test

HOMA-IR, homeostasis model assessment of insulin resistance

However, the differences were not significant $(p=0.08$ for main effect of group).

Fatty acid metabolism Arterial plasma NEFA concentrations (Fig. 2a) tended to be lower in the fasting state in the insulin-resistant group than in the control group, as observed in the cohort study. However, there were no statistically significant differences between the two groups at any time.
Whole-body $\mathrm{Ra}_{\mathrm{NEFA}}$ did not differ between the groups. When $\mathrm{Ra}_{\mathrm{NEFA}}$ was expressed per $\mathrm{kg}$ fat mass, it was lower in the insulin-resistant group than in controls in the fasting state $(p=0.04)$, although not statistically significantly thereafter (Fig. 2b). Adipose tissue NEFA output from adipose tissue (expressed per $100 \mathrm{~g}$ of tissue) (Fig. 2c) was also lower in the fasting state in the insulin-resistant group than in controls $(p=0.04)$. There were no differences in the postprandial period. When adipose tissue NEFA output
Fig. 1 Arterial plasma concentrations of a insulin, b glucose, c triacylglycerol (TG) and d $3 \mathrm{OHB}$ in the fasting state and following a mixed meal in insulin-resistant men (circles) and controls (squares).

Repeated-measures ANOVA showed significant main effect of group on plasma insulin $(p=0.001)$, triacylglycerol $(p=0.001)$ and 3OHB $(p=0.034)$. Dashed vertical line, time at which test meal was given a

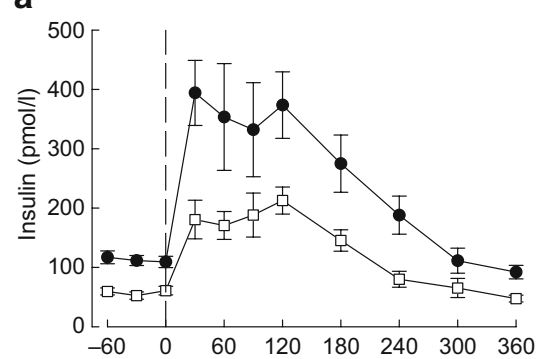

C

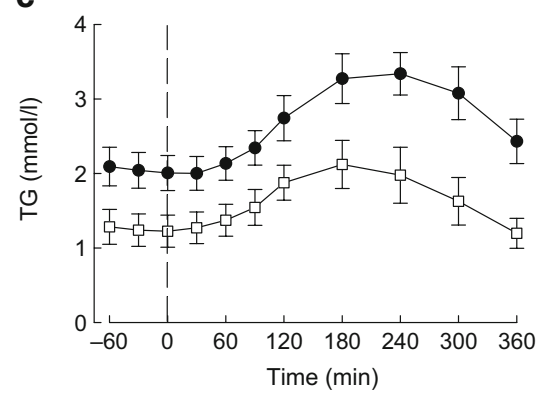

b

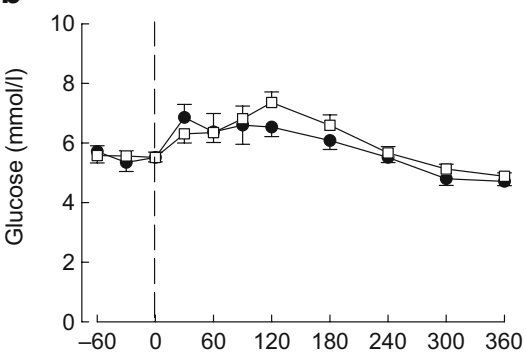

d

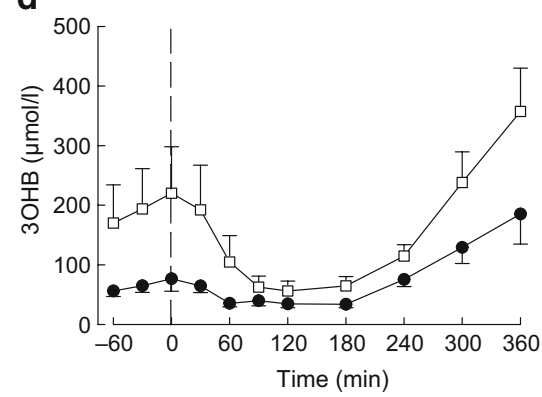


Fig. 2 NEFA metabolism in the fasting state and following a mixed meal in insulin-resistant men (circles) and controls (squares). a Arterial plasma NEFA concentrations, $\mathbf{b}$ rate of appearance of NEFA $\left(\mathrm{Ra}_{\mathrm{NEFA}}\right)$ expressed per $\mathrm{kg}$ fat mass (plotted on a log scale), c subcutaneous abdominal adipose tissue output of NEFA expressed per $100 \mathrm{~g}$ adipose tissue and $\mathbf{d}$ forearm muscle net NEFA uptake. Repeatedmeasures ANOVA showed no significant effects of group over the whole period; differences in the fasting state only are given in the text. Dashed vertical line, time at which test meal was given a
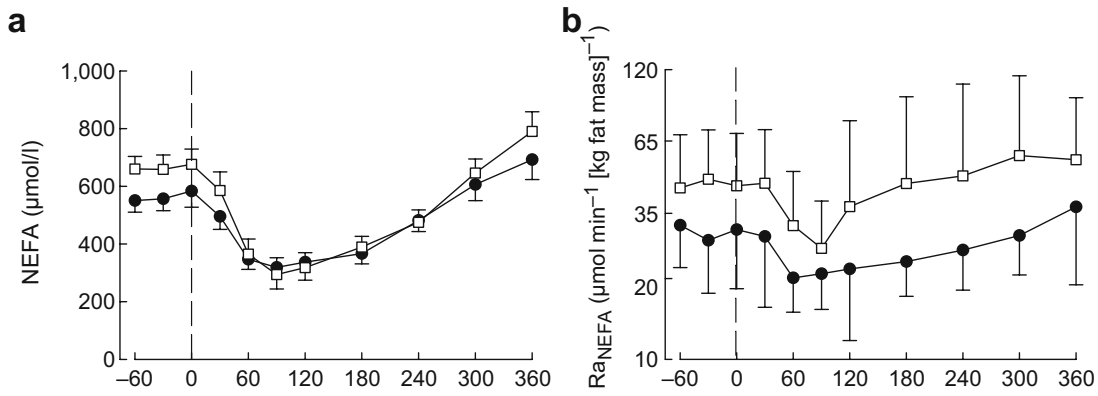

C

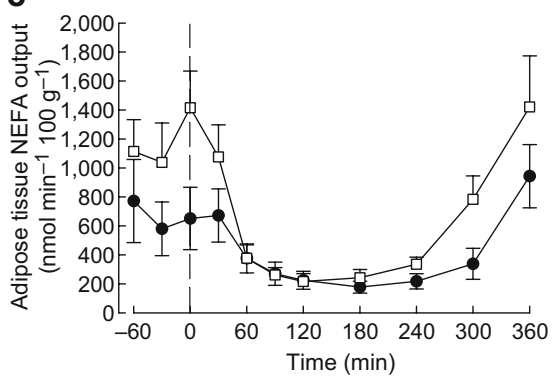

d

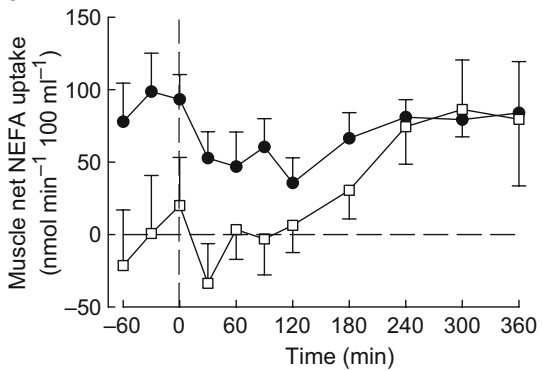

from the subcutaneous abdominal depot was multiplied by whole-body fat mass to obtain an estimate of whole-body NEFA release, the differences between groups disappeared ( $p=0.28$ for fasting values).

Looking at the continuum of fasting plasma insulin concentrations, these were negatively related to fasting values of adipose tissue NEFA release (expressed per $\mathrm{kg}$ adipose tissue, $\left.r_{\mathrm{s}}=-0.53, p=0.02\right)$ and $\mathrm{Ra}_{\mathrm{NEFA}}$ expressed per kg fat mass $\left(r_{\mathrm{s}}=-0.47, p=0.04\right.$; Fig. 3$)$. In other words, the higher the fasting insulin concentration, the lower the rate of fatty acid release per unit weight of adipose tissue. These two measures of NEFA output in relation to fat or adipose tissue mass were themselves correlated $\left(r_{\mathrm{s}}=-0.61\right.$, $p<0.01$ ).

Net uptake of NEFA by forearm muscle was greater in the insulin-resistant group than in the controls in the fasting state (Fig. $2 \mathrm{~d} ; p=0.023$ ), but not thereafter. Forearm muscle absolute (unidirectional) NEFA uptake was calculated using the clearance of $\left[{ }^{2} \mathrm{H}_{2}\right]$ palmitate and the arterial NEFA concentration. It was not different between groups.

Systemic concentrations of non-esterified $\left[\mathrm{U}-{ }^{13} \mathrm{C}\right]$ palmitate were measured as an index of 'spillover' from lipolysis of chylomicron-triacylglycerol [19]. They rose after the meal in both groups, with a peak at $5 \mathrm{~h}$, but were identical in the two groups.

Triacylglycerol metabolism Plasma triacylglycerol was removed by both tissues. Net extraction of plasma triacylglycerol (arterio-venal difference $\times$ blood flow) was not different between groups either in adipose tissue $(p=0.72)$ or forearm muscle $(p=0.18)$. However, because of the higher arterial triacylglycerol concentration in the insulin-resistant group, triacylglycerol clearance was lower in the insulin-resistant group than in controls, both in adipose tissue (Fig. 4a) and in muscle (Fig. 4b).

$\left[\mathrm{U}_{-}{ }^{13} \mathrm{C}\right]$ Palmitic acid, given with the meal, appeared in plasma triacylglycerol by $60 \mathrm{~min}$. Arterial $\left[\mathrm{U}-{ }^{13} \mathrm{C}\right]$ palmitatein-triacylglycerol concentrations rose to a peak at $240 \mathrm{~min}$ (insulin-resistant group) and $180 \mathrm{~min}$ (controls), with significantly higher concentrations in the former (Fig. 4c). Net extraction of $\left[\mathrm{U}-{ }^{13} \mathrm{C}\right]$ palmitate-in-triacylglycerol was very similar in the two groups in each tissue. However, $\left[\mathrm{U}-{ }^{13} \mathrm{C}\right]$ palmitate-in-triacylglycerol clearance in adipose tissue was consistently lower in the insulin-resistant group

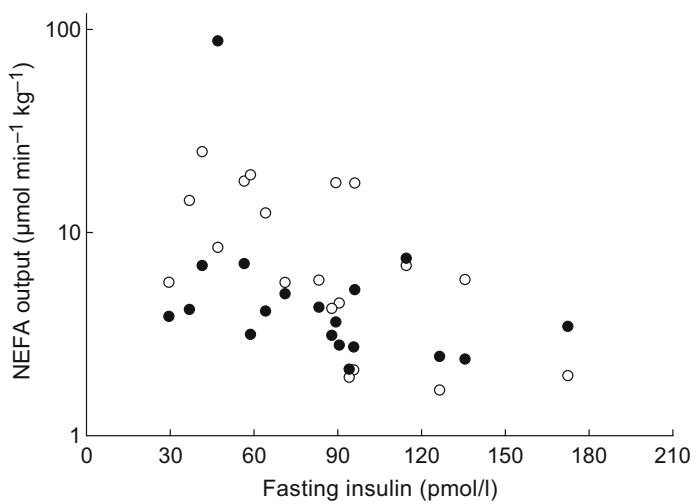

Fig. 3 Relationship between the fasting plasma insulin concentration and measures of NEFA output in the whole group. White circles, NEFA output from subcutaneous abdominal adipose tissue (i.e. venoarterial difference $\times$ blood flow; $r_{s}=-0.53, p=0.02$ ); black circles, $\mathrm{Ra}_{\text {NEFA }}$ expressed per kg fat mass $\left(r_{s}=-0.47, p=0.04\right)$. Both measures of NEFA output are expressed in $\mu \mathrm{mol} \mathrm{min}{ }^{-1}$ ( $\mathrm{kg}$ fat mass or adipose tissue $)^{-1}$. NEFA output is plotted on a log scale to accommodate one outlier for $\mathrm{Ra}_{\mathrm{NEFA}}$ (included in the statistics) 

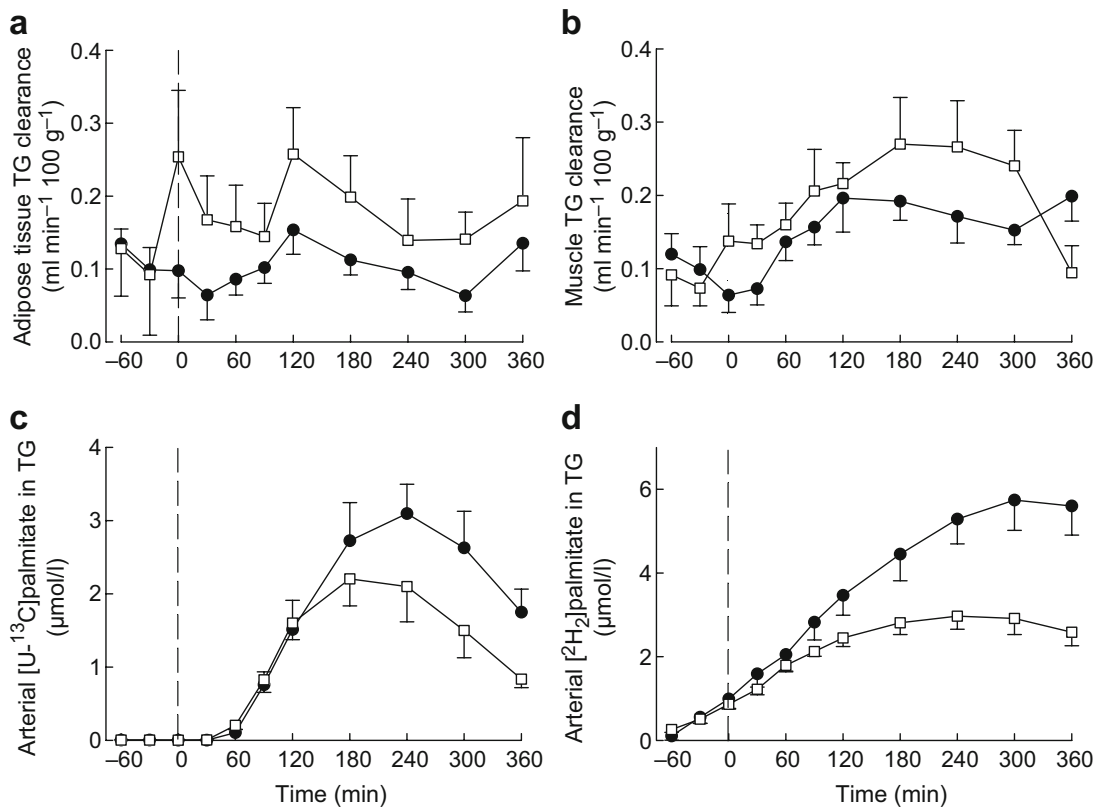

Fig. 4 Triacylglycerol (TG) metabolism in the fasting state and following a mixed meal in insulin-resistant men (circles) and controls (squares). a Subcutaneous abdominal adipose tissue TG clearance, b forearm muscle TG clearance, $\mathbf{c}$ arterial plasma concentrations of $\left[\mathrm{U}-{ }^{13} \mathrm{C}\right]$ palmitate-in-triacylglycerol (the tracer given with the meal), and d arterial plasma concentrations of $\left[{ }^{2} \mathrm{H}_{2}\right]$ palmitate-in-triacylglycerol (the tracer infused intravenously). Adipose tissue and muscle TG clearance

than in controls (repeated measures ANOVA, main effect of group, $p=0.005$ ), but this was not the case in forearm muscle.

$\left[{ }^{2} \mathrm{H}_{2}\right]$ Palmitate, infused intravenously, appeared in arterial plasma triacylglycerol from the first baseline sample onwards, reflecting incorporation into VLDL-triacylglycerol. Concentrations of $\left[{ }^{2} \mathrm{H}_{2}\right]$ palmitate-in-triacylglycerol rose to maximum values at $300 \mathrm{~min}$ (insulin-resistant group) or $240 \mathrm{~min}$ (controls) and were consistently lower in the controls (Fig. 4d). $\left[{ }^{2} \mathrm{H}_{2}\right]$ Palmitate-in-triacylglycerol removal across tissues was small, with inconsistent differences between groups.

\section{Discussion}

We expected to show increased subcutaneous adipose tissue NEFA release, leading to elevated NEFA concentrations in insulin resistance, in line with previous observations in the literature [9-11]. Instead, we found that systemic NEFA concentrations were not elevated in insulin-resistant men compared with controls and that NEFA release (expressed per unit weight of adipose tissue) was somewhat lower in the insulin-resistant men. Our results strongly suggest that NEFA release from subcutaneous adipose tissue tended to be suppressed by the elevated insulin concentrations in the

were each lower in the postprandial state in the insulin-resistant group than in controls (adipose tissue, comparison of AUCs 0-360 min, $p=0.036$; muscle, repeated measures ANOVA, $p=0.01$ ). Arterial $\left[\mathrm{U}-{ }^{13} \mathrm{C}\right]$ palmitate-in-triacylglycerol and $\left[{ }^{2} \mathrm{H}_{2}\right]$ palmitate-in-triacylglycerol concentrations were each higher in the insulin-resistant group (repeatedmeasures ANOVA, group $\times$ time effect, $p=0.001$ and $p<0.001$ respectively). Dashed vertical line, time at which test meal was given

insulin-resistant men. Insulin resistance in our study was far more clearly related to elevated triacylglycerol concentrations than to any alteration in systemic NEFA concentrations.

In comparing these results with other studies with apparently conflicting results, it is important to bear in mind several points about the design of this study. We chose men from a restricted range of BMI, in which it is known that there is a wide variation in insulin sensitivity [28]. We hoped to be able to select insulin-resistant men and controls with similar BMI. In this we were moderately but not entirely successful. In the metabolic study, there was a small difference in fat mass, although BMI did not differ significantly between the groups. Nevertheless, our study is clearly different from those in which obese participants have been compared with lean ones. We also chose a healthy non-diabetic population, so our data are not confounded by impaired glycaemic regulation or insulin deficiency. In addition, we conducted a study in which the participants received a meal rather than a controlled infusion of insulin. Under these conditions, insulin-resistant participants will respond (by definition) with an increased insulin response. It might be argued that, if an increased insulinaemic response is required to bring about normal regulation of NEFA metabolism, then NEFA metabolism in such persons is 'insulin-resistant'. However, another way of looking at this would be that adipose tissue responsiveness 
to insulin has been adjusted to suit the prevailing hyperinsulinaemia. If insulin-sensitivity of lipolysis were to be tested by infusion of insulin to produce pre-defined concentrations, clearly the insulin-resistant men would also appear insulin-resistant in this respect, compared with controls. This has been noted in studies of fatty acid metabolism in obesity: the dose-response curve for suppression of lipolysis by insulin is shifted to the right, but at the same time fat mobilisation is downregulated by the hyperinsulinaemia [29].

Another way of looking at our results would be that compensation for the increased fat mass occurs in the insulin-resistant group, through increased insulin concentrations, bringing about a normalisation of NEFA concentrations. Many other studies can be interpreted in this context. In the study of Opie and Walfish, as noted earlier, a more than tenfold increase in fat mass was accompanied by a relatively small increase in plasma NEFA concentration [5]. In the young massively obese and insulin-resistant women studied by Reeds et al. [17], very high fasting insulin concentrations were apparently sufficient to bring about complete normalisation of plasma NEFA concentrations. This interpretation suggests that there are mechanisms that downregulate adipose tissue lipolysis as fat mass increases. Part of this may be the accompanying hyperinsulinaemia, but it has frequently been observed that the catecholamine-stimulation of lipolysis is reduced in obesity [30]. This may be brought about at a molecular level by reduced expression of the key lipolytic enzymes, adipose triacylglycerol lipase and hormone-sensitive lipase [31]. Presumably these mechanisms reinforce, in the longer term, the direct suppressive effect of the increased insulin concentration.

Our arterio-venal difference measurements were made across subcutaneous adipose tissue. There is substantial evidence, although by no means consistent, that visceral fat depots are more closely associated with insulin resistance, as reviewed (for and against) [32-34]. However, it is clear from our own data in the present and an earlier [35] study, as well as from the work of others [7], that abdominal subcutaneous adipose tissue is the major determinant of systemic NEFA concentrations. The present study does not address other potential links between visceral fat and insulin resistance, for instance those potentially mediated by adipokines.

The close association between insulin resistance and hypertriacylglycerolaemia has been recognised for decades $[36,37]$. Elevated triacylglycerol concentrations in both the fasting and postprandial states were a far more striking accompaniment to insulin resistance in our study than any alteration in NEFA metabolism. We examined triacylglycerol removal in two of the major tissues involved in this process, adipose tissue and skeletal muscle. Although some reduction in triacylglycerol clearance was seen in these tissues, that is likely to be simply a reflection of the elevated triacylglycerol concentrations, with non-linear removal kinetics. It seems unlikely that the relatively small differences in peripheral triacylglycerol clearance would account for the elevation of triacylglycerol concentrations observed, in particular since the defects in clearance were not so evident in the fasting state. Our data do not suggest that over-supply of systemic NEFA could have accounted for increased triacylglycerol production, although there may have been increased fatty acid delivery from 'splanchnic' sources, as we have shown recently in insulin-resistant men [38]. It seems likely that the elevation of triacylglycerol concentrations mainly reflects altered metabolic partitioning of fatty acids within the liver. The reduction in circulating $3 \mathrm{OHB}$ concentrations in the insulin-resistant group would support the idea that fatty acids were preferentially delivered to esterification rather than oxidation in the insulin-resistant group. It could well be that the elevated insulin concentrations played a role in this metabolic switch. The more rapid rate of appearance of the infused fatty acid tracer, $\left[{ }^{2} \mathrm{H}_{2}\right]$ palmitate, in plasma triacylglycerol in the insulin-resistant group reinforces the idea of a primarily hepatic origin for the increased triacylglycerol concentrations.

Taken as a whole, our data fit best with the concept that the small difference in fat mass between the groups led to a difference in the insulin sensitivity of glucose metabolism. The resultant hyperinsulinaemia in the insulin-resistant men was sufficient to normalise glucose metabolism and to downregulate fat mobilisation just sufficiently to normalise circulating NEFA concentrations. An additional effect was an altered metabolic partitioning of fatty acids in the liver towards triacylglycerol synthesis. This view fits perfectly with the recent demonstration that the key change underlying the metabolic alterations of the metabolic syndrome is a defect in muscle insulin resistance [39]. What remains unexplained is how the small increase in fat mass led to muscle insulin resistance (or vice versa).

Acknowledgements We thank L. Dennis and J. Cheeseman for expert nursing assistance with the clinical studies and A. Gijsen and A. Rousseau for technical assistance. This work was supported by NovoNordisk A/S. F. Karpe is a Welcome Trust Senior Clinical Research Fellow.

Duality of interest At the time of the study, H. Tornqvist was an employee of NovoNordisk. The other authors declare that there is no duality of interest associated with this manuscript.

\section{References}

1. Reaven GM (1988) Role of insulin resistance in human disease. Diabetes 37:1595-1607

2. Eckel RH, Grundy SM, Zimmet PZ (2005) The metabolic syndrome. Lancet 365:1415-1428 
3. Kahn SE, Hull RL, Utzschneider KM (2006) Mechanisms linking obesity to insulin resistance and type 2 diabetes. Nature 444:840846

4. Unger RH (2003) Minireview: weapons of lean body mass destruction: the role of ectopic lipids in the metabolic syndrome. Endocrinology 144:5159-5165

5. Opie LH, Walfish PG (1963) Plasma free fatty acid concentrations in obesity. N Engl J Med 268:757-760

6. Groop LC, Bonadonna RC, Simonson DC, Petrides AS, Shank M, DeFronzo RA (1992) Effect of insulin on oxidative and nonoxidative pathways of free fatty acid metabolism in human obesity. Am J Physiol 263:E79-E84

7. Nielsen S, Guo Z, Johnson CM, Hensrud DD, Jensen MD (2004) Splanchnic lipolysis in human obesity. J Clin Invest 113:15821588

8. Guo Z, Hensrud DD, Johnson CM, Jensen MD (1999) Regional postprandial fatty acid metabolism in different obesity phenotypes. Diabetes 48:1586-1592

9. Baldeweg SE, Golay A, Natali A, Balkau B, Del Prato S, Coppack SW (2000) Insulin resistance, lipid and fatty acid concentrations in 867 healthy Europeans. European Group for the Study of Insulin Resistance (EGIR). Eur J Clin Invest 30:4552

10. Coppack SW, Evans RD, Fisher RM et al (1992) Adipose tissue metabolism in obesity: lipase action in vivo before and after a mixed meal. Metabolism 41:264-272

11. Laws A, Hoen HM, Selby JV, Saad MF, Haffner SM, Howard BV (1997) Differences in insulin suppression of free fatty acid levels by gender and glucose tolerance status. Relation to plasma triglyceride and apolipoprotein B concentrations. Insulin Resistance Atherosclerosis Study (IRAS) Investigators. Arterioscler Thromb Vasc Biol 17:64-71

12. Groop LC, Bonadonna RC, DelPrato S et al (1989) Glucose and free fatty acid metabolism in non-insulin-dependent diabetes mellitus. Evidence for multiple sites of insulin resistance. J Clin Invest 84:205-213

13. Colberg SR, Simoneau JA, Thaete FL, Kelley DE (1995) Skeletal muscle utilization of free fatty acids in women with visceral obesity. J Clin Invest 95:1846-1853

14. Mensink M, Blaak EE, van Baak MA, Wagenmakers AJ, Saris WH (2001) Plasma free fatty acid uptake and oxidation are already diminished in subjects at high risk for developing type 2 diabetes. Diabetes 50:2548-2554

15. Blaak EE, Wagenmakers AJ, Glatz JF et al (2000) Plasma FFA utilization and fatty acid-binding protein content are diminished in type 2 diabetic muscle. Am J Physiol Endocrinol Metab 279: E146-E154

16. Risérus U, Sprecher D, Johnson T et al (2007) Activation of peroxisome proliferator-activated receptor (PPAR) $\delta$ promotes reversal of multiple metabolic abnormalities, reduces oxidative stress, and increases fatty acid oxidation in moderately obese men. Diabetes 57:332-339

17. Reeds DN, Stuart CA, Perez O, Klein S (2006) Adipose tissue, hepatic, and skeletal muscle insulin sensitivity in extremely obese subjects with acanthosis nigricans. Metabolism 55:1658-1663

18. Bagdade JD, Porte D, Bierman EL (1969) The interaction of diabetes and obesity on the regulation of fat mobilization in man. Diabetes 18:759-772

19. Bickerton AS, Roberts R, Fielding BA et al (2007) Preferential uptake of dietary fatty acids in adipose tissue and muscle in the postprandial period. Diabetes 56:168-176
20. Tan GD, Neville MJ, Liverani E et al (2006) The in vivo effects of the Pro12Ala PPAR $\gamma 2$ polymorphism on adipose tissue NEFA metabolism: the first use of the Oxford Biobank. Diabetologia 49:158-168

21. Coppack SW, Fisher RM, Gibbons GF et al (1990) Postprandial substrate deposition in human forearm and adipose tissues in vivo. Clin Sci (Lond) 79:339-348

22. Larsen OA, Lassen NA, Quaade F (1966) Blood flow through human adipose tissue determined with radioactive xenon. Acta Physiol Scand 66:337-345

23. Greenfield ADM, Whitney RJ, Mowbray JF (1963) Methods for the investigation of peripheral blood flow. Br Med Bull 19:101109

24. Matthews DR, Hosker JP, Rudenski AS, Naylor BA, Treacher DF, Turner RC (1985) Homeostasis model assessment: insulin resistance and beta cell function from fasting plasma glucose and insulin concentrations in man. Diabetologia 28:412-419

25. Frayn KN, Coppack SW (2001) Assessment of white adipose tissue metabolism by measurement of arteriovenous differences. Methods Mol Biol 155:269-279

26. Wolfe RR (1992) Radioactive and stable isotope tracers in biomedicine. Wiley-Liss, New York

27. Miles JM, Ellman MG, McClean KL, Jensen MD (1987) Validation of a new method for determination of free fatty acid turnover. Am J Physiol 252:E431-E438

28. Clausen JO, Borch-Johnsen K, Ibsen H et al (1996) Insulin sensitivity index, acute insulin response, and glucose effectiveness in a population-based sample of 380 young healthy Caucasians. Analysis of the impact of gender, body fat, physical fitness, and life-style factors. J Clin Invest 98:1195-1209

29. Campbell PJ, Carlson MG, Nurjhan N (1994) Fat metabolism in human obesity. Am J Physiol 266:E600-E605

30. Arner P (1999) Catecholamine-induced lipolysis in obesity. Int J Obes 23(Suppl 1):10-13

31. Jocken JW, Langin D, Smit E et al (2007) Adipose triglyceride lipase and hormone-sensitive lipase protein expression is decreased in the obese insulin-resistant state. J Clin Endocrinol Metab 92:2292-2299

32. Lebovitz HE, Banerji MA (2005) Point: visceral adiposity is causally related to insulin resistance. Diabetes Care 28:2322-2325

33. Frayn KN (2000) Visceral fat and insulin resistance - causative or correlative? Brit J Nutr 83(Suppl 1):S71-S77

34. Miles JM, Jensen MD (2005) Counterpoint: visceral adiposity is not causally related to insulin resistance. Diabetes Care 28:23262328

35. Frayn KN, Coppack SW, Humphreys SM, Clark ML, Evans RD (1993) Periprandial regulation of lipid metabolism in insulintreated diabetes mellitus. Metabolism 42:504-510

36. Olefsky JM, Farquhar JW, Reaven GM (1974) Reappraisal of the role of insulin in hypertriglyceridaemia. Am J Med 57:551-560

37. Tobey TA, Greenfield M, Kraemer F, Reaven GM (1981) Relationship between insulin resistance, insulin secretion, very low density lipoprotein kinetics, and plasma triglyceride levels in normotriglyceridemic man. Metabolism 30:165-171

38. Hodson L, Bickerton AS, McQuaid SE et al (2007) The contribution of splanchnic fat to VLDL triglyceride is greater in insulin-resistant than insulin-sensitive men and women: studies in the postprandial state. Diabetes 56:2433-2441

39. Petersen KF, Dufour S, Savage DB et al (2007) The role of skeletal muscle insulin resistance in the pathogenesis of the metabolic syndrome. Proc Natl Acad Sci U S A 104:12587-12594 